\title{
Global sinusoidal seasonality in precipitation isotopes
}

\author{
Scott T. Allen ${ }^{1}$, Scott Jasechko ${ }^{2}$, Wouter R. Berghuijs ${ }^{1}$, Jeffrey M. Welker ${ }^{3,4}$, Gregory R. Goldsmith ${ }^{5}$, and \\ James W. Kirchner ${ }^{1,6,7}$ \\ ${ }^{1}$ Department of Environmental Systems Science, ETH Zurich, Zurich, 8092, Switzerland \\ ${ }^{2}$ Bren School of Environmental Science and Management, University of California at Santa Barbara, \\ Santa Barbara, CA, 93117, USA \\ ${ }^{3}$ Ecology and Genetics Research Unit, University of Oulu, 90014 Oulu, Finland \\ ${ }^{4}$ Biological Sciences Department, University of Alaska, Anchorage, Alaska \\ ${ }^{5}$ Schmid College of Science and Technology, Chapman University, Orange CA, 92866, USA \\ ${ }^{6}$ Swiss Federal Research Institute WSL, Birmensdorf, 8903, Switzerland \\ ${ }^{7}$ Department of Earth and Planetary Science, University of California, Berkeley, CA, 94709, USA
}

Correspondence: Scott T. Allen (scott.t.allen@utah.edu)

Received: 4 February 2019 - Discussion started: 20 February 2019

Revised: 4 July 2019 - Accepted: 20 July 2019 - Published: 21 August 2019

\begin{abstract}
Quantifying seasonal variations in precipitation $\delta^{2} \mathrm{H}$ and $\delta^{18} \mathrm{O}$ is important for many stable isotope applications, including inferring plant water sources and streamflow ages. Our objective is to develop a data product that concisely quantifies the seasonality of stable isotope ratios in precipitation. We fit sine curves defined by amplitude, phase, and offset parameters to quantify annual precipitation isotope cycles at 653 meteorological stations on all seven continents. At most of these stations, including in tropical and subtropical regions, sine curves can represent the seasonal cycles in precipitation isotopes. Additionally, the amplitude, phase, and offset parameters of these sine curves correlate with site climatic and geographic characteristics. Multiple linear regression models based on these site characteristics capture most of the global variation in precipitation isotope amplitudes and offsets; while phase values were not well predicted by regression models globally, they were captured by zonal $\left(0-30^{\circ}\right.$ and $\left.30-90^{\circ}\right)$ regressions, which were then used to produce global maps. These global maps of sinusoidal seasonality in precipitation isotopes based on regression models were adjusted for the residual spatial variations that were not captured by the regression models. The resulting mean prediction errors were $0.49 \%$ for $\delta^{18} \mathrm{O}$ amplitude, $0.73 \%$ for $\delta^{18} \mathrm{O}$ offset (and $4.0 \%$ and $7.4 \%$ for $\delta^{2} \mathrm{H}$ amplitude and offset), $8 \mathrm{~d}$ for phase values at latitudes outside of $30^{\circ}$, and $20 \mathrm{~d}$ for phase values at latitudes inside of $30^{\circ}$. We make the gridded global maps of precipitation $\delta^{2} \mathrm{H}$ and $\delta^{18} \mathrm{O}$ seasonal-
\end{abstract}

ity publicly available. We also make tabulated site data and fitted sine curve parameters available to support the development of regionally calibrated models, which will often be more accurate than our global model for regionally specific studies.

\section{Introduction}

Characterizing the stable oxygen $\left({ }^{18} \mathrm{O} /{ }^{16} \mathrm{O}\right)$ and hydrogen $\left({ }^{2} \mathrm{H} /{ }^{1} \mathrm{H}\right)$ isotope compositions of precipitation can provide insights into the temporal and spatial origins of water, and of geological and biological materials that incorporate $\mathrm{O}$ and $\mathrm{H}$ from water. However, the isotopic composition of precipitation is difficult and costly to measure across large spatial scales or at high temporal frequencies, and thus precipitation isotope measurements are often unavailable for the times and locations at which they are needed. Consequently, compiled precipitation isotope data (e.g., Global Network for Isotopes in Precipitation; International Atomic Energy Agency) and interpolations of mean and monthly precipitation isotope data (e.g., Bowen et al., 2005; Bowen and Wilkinson, 2002) are used across many fields of science (West et al., 2010).

Although these network datasets and interpolated maps contain spatial and temporal information, it is often convenient to simplify and average across one of those dimensions. When identifying the spatial origin of water in a sam- 
ple, investigators may use spatial patterns in mean isotope ratios (despite those patterns varying temporally and those samples not integrating water signatures throughout years). Additionally, when identifying the temporal origin of water in a sample, investigators often use time series of isotope data from the nearest measurement location (and thus do not account for spatial differences). Alternatively, concise representations of large-scale spatiotemporal precipitation isotope patterns could be widely useful and mitigate the need to average precipitation isotope data across space or time. Various tools and interpolation schemes exist for predicting precipitation isotope ratios at a given location (e.g., Online Isotopes in Precipitation Calculator following Bowen and Revenaugh, 2003), or for mapping spatial patterns in mean or monthly values over specified intervals (e.g., https://isomap.rcac.purdue.edu/isomap/, last access: $11 \mathrm{Au}-$ gust 2019; see Bowen et al., 2014). However, previous methods have not explicitly supported predictions of seasonal isotope cycles by first using metrics that capture isotopic temporal dynamics and then interpolating those metrics.

Isotope ratios in precipitation often follow distinct seasonal cycles that can be approximated by sine curves (Bowen, 2008; Dutton et al., 2005; Feng et al., 2009; Halder et al., 2015; Vachon et al., 2007; Wilkinson and Ivany, 2002), and the parameters describing those sine curves are often predictable in space (Allen et al., 2018; Jasechko et al., 2016). Sine curves concisely represent temporal dynamics because they express continuous, cyclic time series as functions of only three parameters (amplitude, phase, and offset). To predict isotope seasonality across the globe, values of these three sine parameters, fitted to monthly precipitation isotope data at monitoring stations, can be described as functions of station climate and geography. Such mapped sinusoidal cycles were shown to be effective in predicting monthly precipitation isotope values across Switzerland (Allen et al., 2018). Beyond being useful for predicting isotope values in specific seasons, sine curves generally aid in characterizing the propagation of cyclic signals. For example, as precipitation travels through hillslopes and into streams, seasonal isotope amplitudes are dampened, reflecting transport processes that can be quantified as a ratio of stream and precipitation amplitudes (Kirchner, 2016a, b); this young water fraction, which requires sine curve fitting of precipitation isotopes, has been used in many recent studies (Clow et al., 2018; von Freyberg et al., 2018; Jacobs et al., 2018; Jasechko et al., 2016, 2017; Lutz et al., 2018; Song et al., 2017). Thus, there are immediate applications for mapped sine curves that characterize precipitation isotope cycles across the globe. More generally, spatial data describing how precipitation isotope compositions vary seasonally could facilitate interpretations of environmental ${ }^{18} \mathrm{O} /{ }^{16} \mathrm{O}$ and ${ }^{2} \mathrm{H} /{ }^{1} \mathrm{H}$ data and support predictions of precipitation isotope compositions in time and space.

Here we present global maps of precipitation isotope cycles that capture patterns in precipitation isotope seasonality. We first describe the strength of seasonal isotope cycles and quantify how well sine curves explain monthly precipitation measurements at each of 653 precipitation isotope monitoring stations. We then explore how well the parameters describing those sine curves can be predicted across the globe, as a function of site characteristics. Lastly, we produce global maps and data that support stable isotope applications and make these maps and data publicly available. We conduct these analyses to support a growing need for quantifications of seasonal cycles in precipitation isotopes, not to challenge the methods previously used in other precipitation isotope models.

\section{Methods}

\subsection{Data}

We used a global dataset of monthly precipitation oxygen and hydrogen isotope measurements from 650 and 610 precipitation monitoring stations, respectively. These previously compiled (Jasechko et al., 2016) data were collected from the Canadian Network for Isotopes in Precipitation (Birks and Edwards, 2009; Birks and Gibson, 2013), the US Network for Isotopes in Precipitation (Delavau et al., 2015; Welker, 2000, 2012), and the Global Network for Isotopes in Precipitation (Aggarwal et al., 2011; Halder et al., 2015). Following Jasechko et al. (2016), we characterize seasonal cycles only at monitoring stations that report precipitation isotope compositions for at least eight unique months. Monthly precipitation amounts (or snow-water equivalencies) are also available from 623 of the 650 stations that measured oxygen isotope ratios, and from 603 of the 610 stations that measured hydrogen isotope ratios. All hydrogen and oxygen isotope ratios of precipitation are denoted as $\delta^{2} \mathrm{H}$ and $\delta^{18} \mathrm{O}$, defined by

$\delta^{2} \mathrm{H}=\frac{\left({ }^{2} \mathrm{H} /{ }^{1} \mathrm{H}\right)_{\text {sample }}-\left({ }^{2} \mathrm{H} /{ }^{1} \mathrm{H}\right)_{\text {V-SMOW }}}{\left({ }^{2} \mathrm{H} /{ }^{1} \mathrm{H}\right)_{\text {V-SMOW }}} \times 1000 \%$,

and

$\delta^{18} \mathrm{O}=\frac{\left({ }^{18} \mathrm{O} /{ }^{16} \mathrm{O}\right)_{\text {sample }}-\left({ }^{18} \mathrm{O} /{ }^{16} \mathrm{O}\right)_{\text {V-SMOW }}}{\left({ }^{18} \mathrm{O} /{ }^{16} \mathrm{O}\right)_{\text {V-SMOW }}} \times 1000 \%$,

where V-SMOW refers to the Vienna Standard Mean Ocean Water standard.

We compiled gridded climatological and geographical data for global modeling and for inferring site characteristics of the precipitation monitoring stations (Fig. 1). We downloaded climate maps of monthly precipitation sums and monthly means of daily low, high, and mean temperature, all at 5 arcmin (i.e., $0.083^{\circ}$ ) resolution (WorldClim; Fick and Hijmans, 2017). Station climate data were inferred from these gridded products for all but three stations that were on small islands or stationary weather vessels, for which local meteorological data were acquired. The range of mean monthly 
(a) Elevation

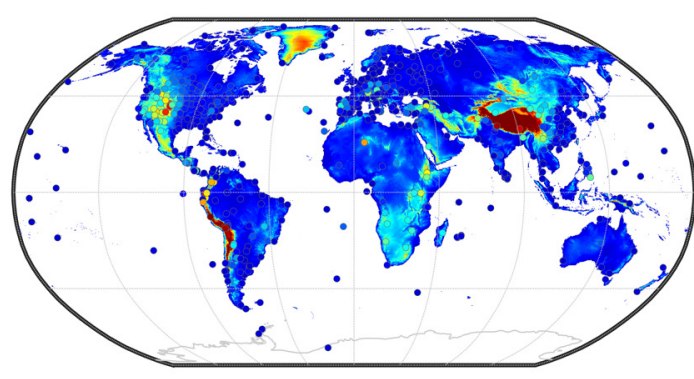

(b) Distance from coast

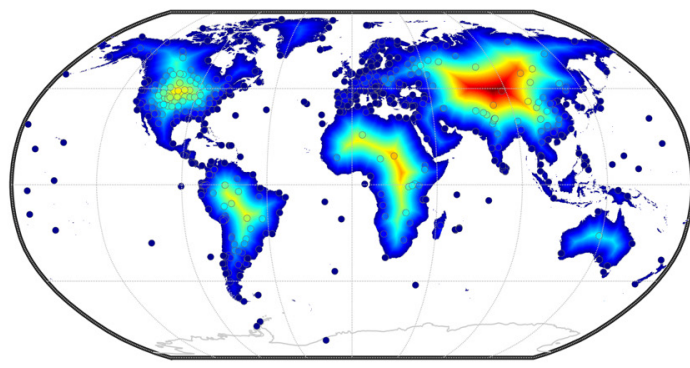

(m a.s.l.)

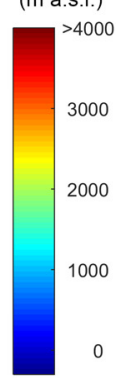

(d) Mean annual temperature

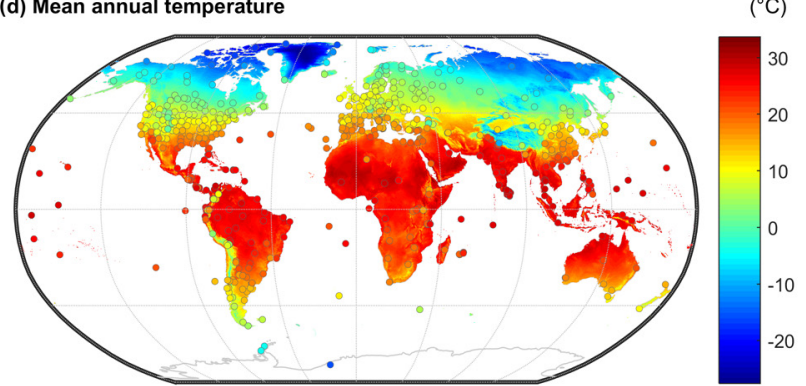

(c) Seasonal temperature range

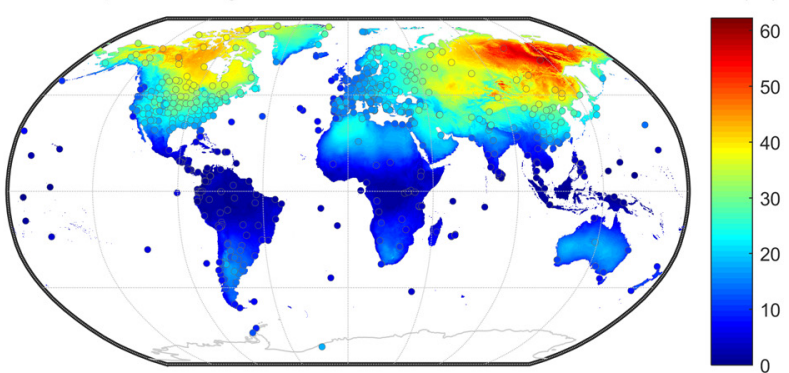

(km)

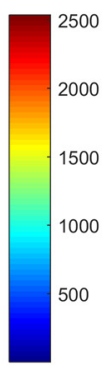

(e) Mean annual precipitation

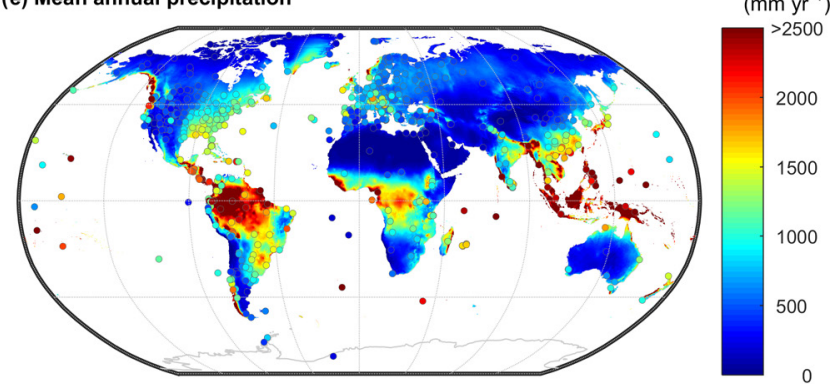

Figure 1. Global maps of site characteristics used for predicting seasonal precipitation isotope cycles: (a) elevation of precipitation isotope monitoring stations plotted over the elevation map, (b) distance from coast, (c) temperature range between mean temperatures of warmest and coldest months, (d) mean annual temperature, and (e) mean annual precipitation. Values at precipitation isotope monitoring stations are marked by circles. For b-e, station-level data are estimated as the value of the grid cells that the stations occupy.

temperatures was computed at each pixel (and each monitoring station) as the difference between the highest and lowest monthly mean values, using the WorldClim data. Annual mean daily temperature range was calculated as the mean differences between daily minimum and maximum temperatures. The WorldClim data were also used to calculate time of peak precipitation and temperature, and seasonal amplitude of precipitation and temperature, metrics which can together capture global patterns in hydroclimate (Berghuijs and Woods, 2016). We also used a $30 \mathrm{~s}$ gridded elevation map (GTOPO30; US Geological Survey, 1996) that was aggregated to $5 \mathrm{~min}$ for consistency with the other grids. Monitoring station elevation data were not inferred from the grids, but instead downloaded directly from the isotope network databases. Distance from oceans and seas was calculated in ArcGIS 10.4.1 (ESRI, Redlands, USA) using published coastline data (Wessel and Smith, 1996) for the center of each 5 min pixel and for each monitoring station.

\subsection{Sine-fitting methods}

We fitted sine curves (described by the parameters amplitude, phase, and offset) to each monitoring station's monthly measured $\delta^{18} \mathrm{O}$ and $\delta^{2} \mathrm{H}$ time series using a nonlinear fitting routine ("fitnlm" in MATLAB R2016B, Mathworks, Natick, Massachusetts, USA). The sine curve is defined with a fixed period of 1 year, 
precipitation $\delta^{18} \mathrm{O}$ or $\delta^{2} \mathrm{H}(t)=$ amplitude

$$
\times \sin (2 \pi t-\text { phase })+\text { offset, }
$$

where $t$ is the fractional year.All fitted amplitudes and phases were adjusted so that fitted amplitude values are positive, and phase values are between $\pi$ and $-\pi$. Phase was calculated in radians, but we report all values in days from the summer solstice. Allen et al. (2018) previously confirmed that this nonlinear fitting routine yields parameter values and component standard errors that are equivalent to those obtained by fitting sine curves as an additive model of sine and cosine functions with their uncertainties calculated by Gaussian error propagation. It should be noted that standard errors depend on the length of records, and while some stations have datasets that are as long as 57 years, shorter durations are more common (Fig. 2a). We fitted the sine curves by two alternative approaches: (a) using iteratively reweighted least squares with a bisquare weighting function (robustly fitted), and (b) using standard least squares with the influence of each monthly isotope measurement weighted by the amount of precipitation during that month (amount-weighted). These metrics have different limitations. The amount-weighted cycles are less influenced by erratic values that can occur in low-precipitation months but also do not capture the variations during drier seasons as effectively. For example, if there was an anomalously dry month in a short data record and that dry month also had an atypical isotope value (e.g., because it was composed of a single small event), that value could result in a robust-fit exaggerating the true seasonal isotope cycle. If estimates based on that sinusoid were later weighted with typical precipitation amounts, this could introduce errors. Weighted fits could introduce errors if drier season precipitation is important to the study system, but the dry season precipitation has minimal influence on the fits and thus those values are misrepresented. Weighted fits might also mischaracterize the seasonal dynamics of a typical year in regions that are impacted by extreme precipitation in some years (e.g., hurricanes or monsoons) if that extreme precipitation has distinct isotope values and yields volumes that are substantial fractions of annual precipitation (e.g., Price et al., 2008). We focus on the robustly fitted parameters describing the seasonal cycles, but for comparison, the amount-weighted fits are also reported in Supplement 2. We recommend that future users of these data carefully consider the different limitations when selecting between these two approaches.

\subsection{Precipitation sinusoidal prediction methods}

To characterize spatial variations in precipitation isotope seasonality, we establish relationships between the fitted sine parameters (amplitude, phase, and offset) and site characteristics of the precipitation isotope monitoring stations using multiple linear regression. To characterize the monitoring stations, we used elevation, absolute latitude, distance
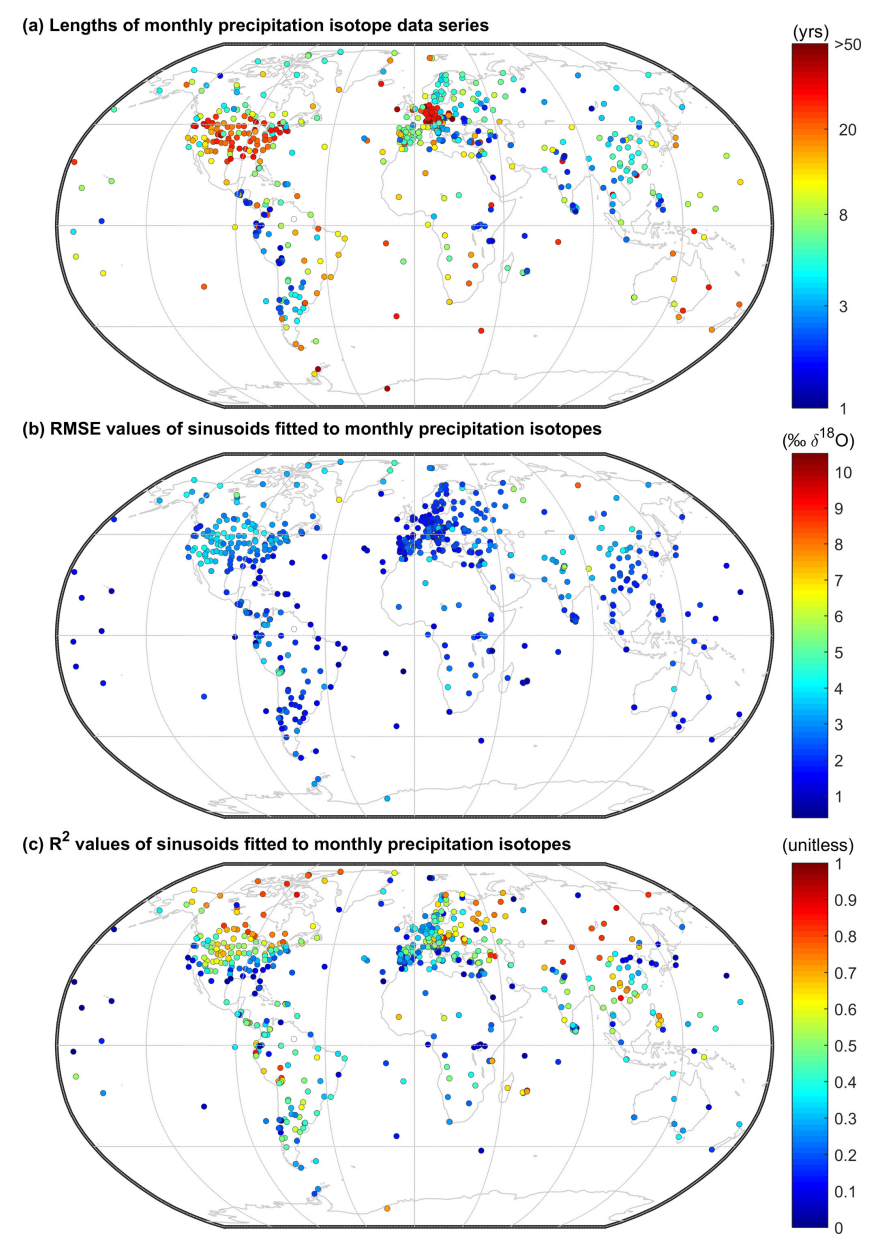

Figure 2. Maps of precipitation isotope measurement stations with colors indicating (a) the length of measurements at each site, and goodness-of-fit, statistics (b) root mean square errors (RMSEs) and (c) coefficients of variations $\left(R^{2}\right)$ of the fitting of sine curves to monthly, empirical time series from each station. We show the robustly fitted $\delta^{18} \mathrm{O}$ statistics; the amount-weighted $\delta^{18} \mathrm{O}$ fit statistics, and the $\delta^{2} \mathrm{H}$ statistics (robustly fitted and amount-weighted) are provided in the Supplement 2.

from the nearest ocean, mean annual temperature, range of mean monthly temperatures, seasonal amplitude of precipitation amount, and mean annual precipitation amount (Fig. 1). We chose these metrics as spatial predictors because global datasets of these metrics are publicly available and they capture aspects of climate and circulation patterns that are known to affect precipitation isotopic composition (Aggarwal et al., 2016; Birks and Edwards, 2009; Rozanski et al., 1993). To determine which predictors should be included in regression models, we used a stepwise model selection approach in which different combinations of predictors were used to maximize $R^{2}$ values while requiring that all coefficient $p$ values be statistically significant $(p<0.05)$. This step limits model overfitting by excluding redundant or nonsignificant predictors. We found that using these cri- 
teria more aggressively removed variables compared to the more standard Akaike information criterion (AIC). To assess collinearity among these variables, we calculated the variance inflation factors (VIFs) associated with a hypothetical model that includes all six variables; we found those factors to range from 1.4 to 7.8 , and while no fitted models were actually included all six terms, the variance inflation factors among the six predictors are still all below the often-used threshold of 10 (Marquaridt, 1970). After identifying the appropriate model terms, models were fitted using the "fitlm" function with robust fitting options that reduce the influence of outliers (MATLAB R2016B). In preliminary analyses, we also tested other metrics - precipitation phase, temperature phase, and mean daily temperature range - but determined that they were not consistently important (i.e., when included in the initial model selection, they were mostly excluded). Thus we excluded these other metrics from subsequent analyses to avoid overcomplicating the models; however, they often showed interesting relationships with the sine parameters, so they are provided in Fig. S1 in the Supplement.

For models of phase, we only used data from monitoring stations where there is a distinct seasonal cycle, because phase terms are meaningless and fitted values are unstable where there are no sinusoidal seasonal cycles; these phase values will also be excluded from the supporting information data files to avoid confusion. We characterize distinct seasonal cycles as ones where the phase is well constrained, with standard errors of the fitted phase terms lower than $15 \mathrm{~d}$ (and thus $95 \%$ confidence intervals of approximately \pm 1 month). Roughly $74 \%$ of the sites $(n=479)$ met this criterion. We also tested other criteria for filtering out stations with meaningless phase terms, such as $R^{2}>0.3(n=425)$ or $R^{2}>0.5$ $(n=232)$, and those yielded similar regression models for phase. We modeled phase in middle and high latitudes (30 to $90^{\circ} ; n=349$ after removing data without distinct seasonal cycles) separately from phase in tropical and subtropical latitudes $\left(0\right.$ to $30^{\circ} ; n=130$ after removing data without distinct seasonal cycles). We took this approach because initial inspections of these data and past examinations of similar data (Bowen and Revenaugh, 2003; Feng et al., 2009; Halder et al., 2015) suggested that phase is relatively consistent within each of these zones, with sharp transitions at approximately $30^{\circ} \mathrm{N}$ and S (roughly corresponding with Hadley Cell boundaries; Birner et al., 2014).

These fitted spatial regression equations for amplitude, phase, and offset were used to map global precipitation isotope seasonality using the gridded site-characteristic data. We did not extend these maps to extrapolate Antarctic isotope seasonality because there are few monitoring stations there. We also mapped the residuals, estimated by subtracting the regression model estimates of amplitude, phase, and offset from the same variables determined from the fitted sine curves at the precipitation monitoring stations. We interpolated those residuals using inverse-distance weighting of the residual values from the three stations that are most prox- imal to each grid-cell center. For phase, we used nearestneighbor interpolation, rather than inverse-distance weighting, because averages across unlike phases are poorly representative. We then applied a Gaussian filter to smooth each of the residual adjustment layers, with the standard deviation equal to $3^{\circ}$, because we assume there are measurement uncertainties and thus the layer should not be fitted exactly to the points; we smoothed the phase residuals separately in absolute latitudes $>30^{\circ}$ versus absolute latitudes $<30^{\circ}$. For final predictive maps, we added the smoothed residual maps to the regression-based maps; wherever negative amplitudes resulted, those values were forced to zero. Errors were evaluated by running this routine again, but while randomly excluding 65 sites (10\%) for subsequent use as independent quality-control checks. Sine parameters for those 65 stations were predicted using models calibrated with the other $\sim 585$ sites; this Monte Carlo procedure was iterated 15 times for both $\delta^{18} \mathrm{O}$ and $\delta^{2} \mathrm{H}$.

We provide these predictive maps of the gridded amplitude, phase, and offset values of $\delta^{18} \mathrm{O}$ and $\delta^{2} \mathrm{H}$. We also provide gridded amplitude, phase, and offset values for precipitation amount, which can be used to scale precipitation isotopic inputs, in applications where amount is important. These maps are provided (Supplement 3).

To explore sub-global variations in performance of the spatial multiple regression models, we also performed regional regression analyses in which we fitted multiple regressions to data from subsections of the globe. Regressions of amplitude, phase, and offset were calculated for $40^{\circ} \times 40^{\circ}$ windows using the same site characteristics that were used in the global models: absolute latitude, elevation above sea level, distance from coastline, range of mean monthly temperatures, mean annual temperature, and annual precipitation amount. These regional regressions were calculated at all vertices of a $10^{\circ}$ grid (marking the center of each $40^{\circ}$ window). We used the same combination of stepwise regression model selection and robust regression fitting as in the global analysis. Only windows that contained more than 25 precipitation isotope monitoring stations were analyzed. We report gridded $R^{2}$ and root mean square error (RMSE) values to indicate where these relationships are strongest. We also provide fitted sine parameters and site characteristics in the supporting information to facilitate users' development of other regression models for regionally specific applications (Supplement 2).

\section{Results}

\subsection{Seasonal cycles in precipitation isotopes}

Globally, $94 \%$ of the precipitation $\delta^{18} \mathrm{O}$ monitoring stations $(n=650)$ have statistically significant seasonal isotope cycles ( $p<0.05 ; t$ test of the $\delta^{18} \mathrm{O}$ amplitudes), although those cycles do not always explain the majority of the variance 
Table 1. Pearson and Spearman correlation coefficients of sine parameters versus site characteristics.

\begin{tabular}{lrrrrrr}
\hline $\begin{array}{l}\text { Sine } \\
\text { parameters }\end{array}$ & $\begin{array}{r}\text { Versus } \\
\text { |latitude| }\end{array}$ & $\begin{array}{r}\text { Versus } \\
\text { elevation }\end{array}$ & $\begin{array}{r}\text { Versus dist. } \\
\text { from coast }\end{array}$ & $\begin{array}{r}\text { Versus temp. } \\
\text { range }\end{array}$ & $\begin{array}{r}\text { Versus mean } \\
\text { temp. }\end{array}$ & $\begin{array}{r}\text { Versus mean } \\
\text { precip. }\end{array}$ \\
\hline Pearson & & & & & & \\
\hline Amplitude & 0.34 & 0.34 & 0.54 & 0.58 & -0.56 & -0.35 \\
Phase & 0.76 & -0.12 & 0.25 & 0.72 & -0.68 & -0.64 \\
Offset & -0.67 & -0.16 & -0.23 & -0.70 & 0.88 & 0.40 \\
\hline Spearman & & & & & & \\
\hline Amplitude & 0.30 & 0.42 & 0.56 & 0.51 & -0.49 & -0.37 \\
Phase & 0.59 & 0.04 & 0.20 & 0.63 & -0.64 & -0.62 \\
Offset & -0.69 & -0.26 & -0.35 & -0.65 & 0.87 & 0.40 \\
\hline
\end{tabular}
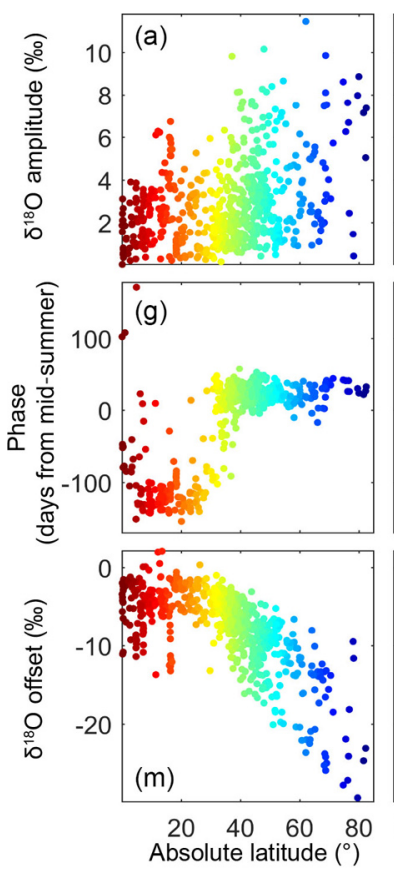
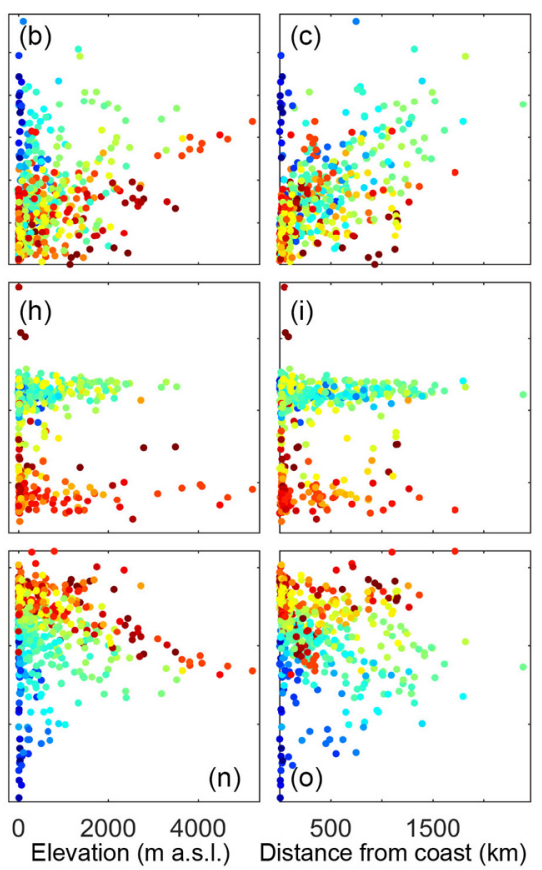

$500 \quad 1500$

Distance from coast $(\mathrm{km})$

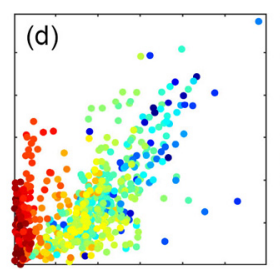

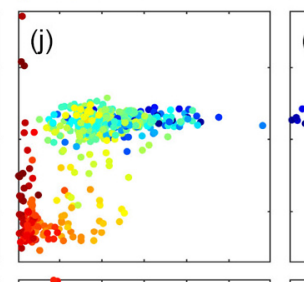
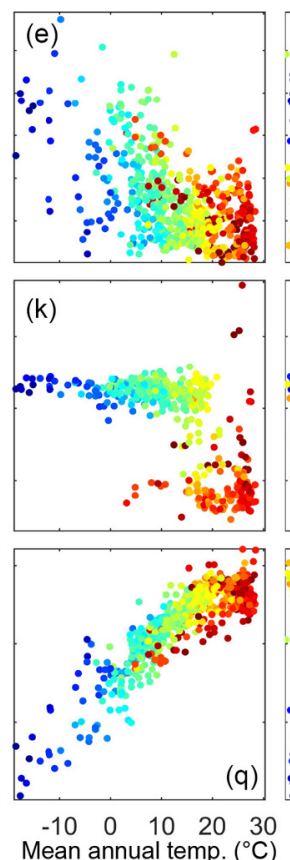

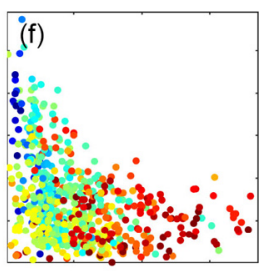

(I)

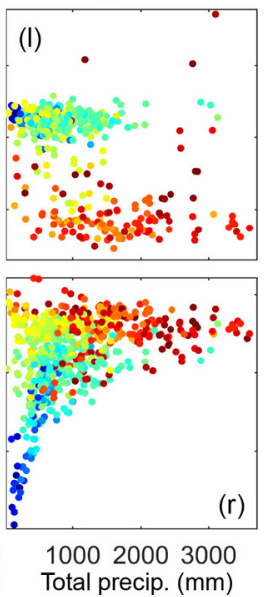

Figure 3. Scatter plots of fitted sine parameters describing precipitation $\delta^{18} \mathrm{O}$ seasonal cycles - (a-f) amplitude, (g-l) phase, $(\mathbf{m}-\mathbf{r})$ offset versus site characteristics. For associated Spearman and Pearson correlation coefficients, see Table 1. Colors indicate absolute latitude (high latitudes in blue, low latitudes in red) as shown in (a), (g), and (m).

in monthly isotope values (i.e., only $36 \%$ of the stations had $R^{2}$ greater than 0.5; Fig. 2). Amplitudes range from 0 to $11 \%$ o $\delta^{18} \mathrm{O}$ (Fig. 3), with a median value of $2.3 \%$ o $\delta^{18} \mathrm{O}$; here, amplitude quantifies the strength of seasonal cycles as deviations from average annual values, so an amplitude of $2.3 \% \circ \delta^{18} \mathrm{O}$ corresponds to a range of $4.6 \%$ obetween typical values in the "higher $\delta^{18} \mathrm{O}$ season" and the "lower $\delta^{18} \mathrm{O}$ season". Seasonal isotope variations are larger in colder, higher-latitude, higher-elevation, or more continental regions (Fig. 3), although no individual site characteristic explains the majority of variation in amplitude (Fig. 3; Table 1). The few coastal stations that have strong seasonal cycles are almost exclusively located in high absolute-latitude regions (Fig. 4a). Many of the monitoring sites within tropical latitudes also have substantial seasonal cycles; for example, $27 \%$ of sites in the tropics show amplitudes greater than $3 \% \circ \delta^{18} \mathrm{O}$, and they are not all high-elevation sites (Fig. 3b).

Although most stations show a seasonal precipitation $\delta^{18} \mathrm{O}$ cycle, the ability of sine curves to capture monthly $\delta^{18} \mathrm{O}$ values varies (Fig. 2). The median percent of variance explained by sine curves is $42 \%$; the median RMSE of individual monthly deviations from fitted sine curves is $2.2 \% \delta^{18} \mathrm{O}$. Stronger fits occur where (a) there is a strong seasonal cycle, (b) the seasonal cycle is the dominant pattern of variation, and (c) sine curves are the appropriate shape to characterize precipitation isotope variations. Accordingly, the spatial pat- 
Table 2. Multiple regression coefficients and fit statistics for models describing global variations in sine parameters that capture seasonal precipitation $\delta^{18} \mathrm{O}$ cycles. Dashes mark predictors that were excluded by the stepwise-regression model selection.

\begin{tabular}{lrrrrrrrrr}
\hline & $\begin{array}{r}\mid \text { Latitude| } \\
\left({ }^{\circ} \text { from }\right. \\
\text { Equator })\end{array}$ & $\begin{array}{r}\text { Elevation } \\
(\mathrm{m} \text { a.m.s.l. })\end{array}$ & $\begin{array}{r}\text { Dist. from } \\
\text { coast } \\
(\mathrm{km})\end{array}$ & $\begin{array}{r}\text { Temp. } \\
\text { range } \\
\left({ }^{\circ} \mathrm{C}\right)\end{array}$ & $\begin{array}{r}\text { Mean annual } \\
\text { temp. } \\
\left({ }^{\circ} \mathrm{C}\right)\end{array}$ & $\begin{array}{r}\text { Mean annual } \\
\text { precip. } \\
\left(\mathrm{mm} \mathrm{yr}^{-1}\right)\end{array}$ & $\begin{array}{r}\text { Intercept } \\
\text { RMSE }\end{array}$ & $R^{2}$ \\
\hline $\begin{array}{l}\text { Amplitude } \\
\left(\% \circ \delta^{18} \mathrm{O}\right)\end{array}$ & -0.06 & 0.0003 & 0.0013 & 0.08 & -0.12 & - & 4.5 & 1.1 & 0.64 \\
\hline $\begin{array}{l}\text { Phase } \\
(\text { days })^{\mathrm{a}}\end{array}$ & - & 0.005 & - & - & -0.38 & - & 24.2 & 12.0 & 0.19 \\
\hline $\begin{array}{l}\text { Phase } \\
(\text { days })^{\mathrm{b}}\end{array}$ & -1.27 & - & - & 0.78 & - & - & -100.0 & 28.2 & 0.21 \\
\hline $\begin{array}{l}\text { Offset } \\
(\% \circ \delta\end{array}$ & 0.10 & - & - & -0.11 & 0.55 & -0.0008 & -15.7 & 2.0 & 0.83 \\
\hline
\end{tabular}

${ }^{\text {a }}$ Referring to sites in latitudes $>30^{\circ}$ (N or S). ${ }^{\text {b }}$ Referring to sites in latitudes $<30^{\circ}$ (N or S).

tern in $R^{2}$ (Fig. 2c) is broadly similar to the pattern in amplitude $(r=0.74)$. However, RMSE also increases with amplitude $(r=0.58)$, demonstrating that greater seasonal variability is also generally associated with greater month-to-month deviations from the seasonal sinusoidal cycle.

The phase term is well constrained (i.e., SE of phase $<15 \mathrm{~d})$ at most but not all sites $(n=479)$, and its geographic distribution is surprisingly binary (Fig. 4b). From $30^{\circ} \mathrm{S}$ to $30^{\circ} \mathrm{N}$ (i.e., roughly corresponding with the Hadley cells), peak isotope values occurred $104 \pm 43 \mathrm{~d}$ before the summer solstice (mean $\pm \mathrm{SD}$ ). By contrast, in the middle- and highlatitude regions, peak isotope values occurred $18.6 \pm 24 \mathrm{~d}$ after the summer solstice. A few exceptions are found in absolute latitudes near $30^{\circ}$, which may be attributable to the effects of the Asian monsoon cycle (Cai et al., 2018) or the migration of Hadley cell boundaries, which do not consistently occur at $30^{\circ}$ (Chen et al., 2014). Peak precipitation isotope values occur within a month of peak temperature at $89 \%$ of the monitoring stations that are in absolute latitudes above $30^{\circ}$ and have well-constrained seasonal isotopic phases (Fig. S2); however, that pattern was not ubiquitous. On average, phase of $\delta^{2} \mathrm{H}$ significantly lags $\delta^{18} \mathrm{O}$ in absolute latitudes over $30^{\circ}(p<0.01)$, albeit with a median difference of only $2 \mathrm{~d}$ (and median absolute difference of $4 \mathrm{~d}$ ); these observations suggest that precipitation line-conditioned (LC) excess, defined as $\delta^{2} \mathrm{H}-a \times \delta^{18} \mathrm{O}-b$ (where $a$ is the slope and $b$ is the intercept of the local meteoric water line (LMWL); (Landwehr and Coplen, 2006), may frequently have a seasonal cycle, as previously described in Switzerland (Allen et al., 2018) and suggested in global deuterium-excess variations (Pfahl and Sodemann, 2014).

Offset values, describing the central tendency of the seasonal cycle, span a range of $33 \%$ in $\delta^{18} \mathrm{O}$. These values are highest (least negative) in tropical and subtropical regions, and lowest in polar regions (Fig. 4c). Most prominent is the strong temperature trend $\left(0.47 \% \circ \delta^{18} \mathrm{O}\right.$ per degree Celsius,
$R^{2}=0.77$; Fig. 3 ; Table 1), consistent with patterns that have been previously described (Dansgaard, 1964; Rozanski et al., 1993). It should be noted that offsets and amplitudes are associated differently with continentality (Fig. 4a, c); while many of the regions with highly negative offsets also have large amplitudes, this is untrue of coastal regions in middle and high latitudes where highly negative offsets and small amplitudes co-occur. For example, in Reykjavik, Iceland, the $\delta^{18} \mathrm{O}$ offset is $-8.0 \%$ and the amplitude is $0.9 \%$; a similar offset is found in continental Iowa, USA $(-8.2 \%$ ), but the amplitude is 4.5 times larger $(4.0 \%$ ).

\subsection{Spatial patterns in parameters describing precipitation isotopic cycles}

The spatial patterns in amplitude, phase, and offset can be described as functions of site characteristics. Of the predictors examined, all have significant correlations (at $p<0.05$ ) with amplitude, phase, and offset (Table 1; see also Fig. 3). Spearman rank correlations, which are less influenced by extreme values, are also statistically significant for all but one of these relationships (Table 1). However, no variables explain the majority of variation in amplitude, and only temperature explained the majority of variation in offsets (Table 1).

We developed multiple linear regression models of site characteristics and sine parameters, and used them to generate maps of $\delta^{18} \mathrm{O}$ sinusoidal cycles (Fig. 4). The multiple regression models explain $64 \%$ of the variation in amplitude $(\mathrm{RMSE}=1.1 \%$ ) and $83 \%$ of the variation in offset $(\mathrm{RMSE}=2.0 \% \mathrm{o})$. The multiple regression models for phase have low $R^{2}$ values $(0.19$ and 0.21 for absolute latitudes above and below $30^{\circ}$, respectively) because there is little variation in phase within each latitude band; thus, phase RMSE values are small (12 and $28 \mathrm{~d}$; Table 2). The coefficients of the multiple regression equations describing mapped precipitation $\delta^{18} \mathrm{O}$ sinusoidal cycles are pre- 


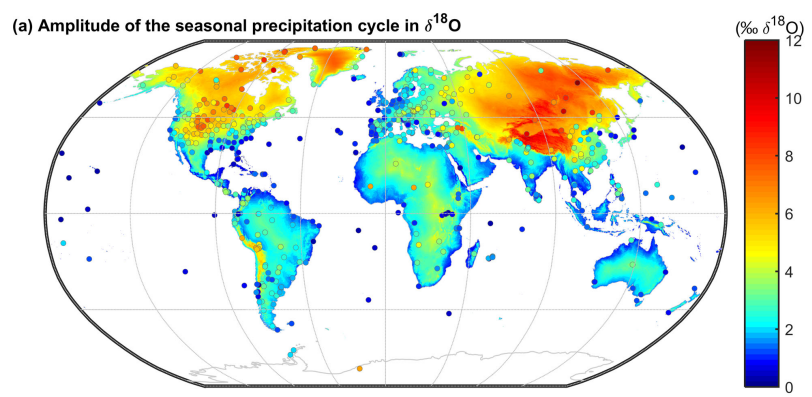

(b) Phase (day of peak value, relative to summer solstice)

(days from summer)
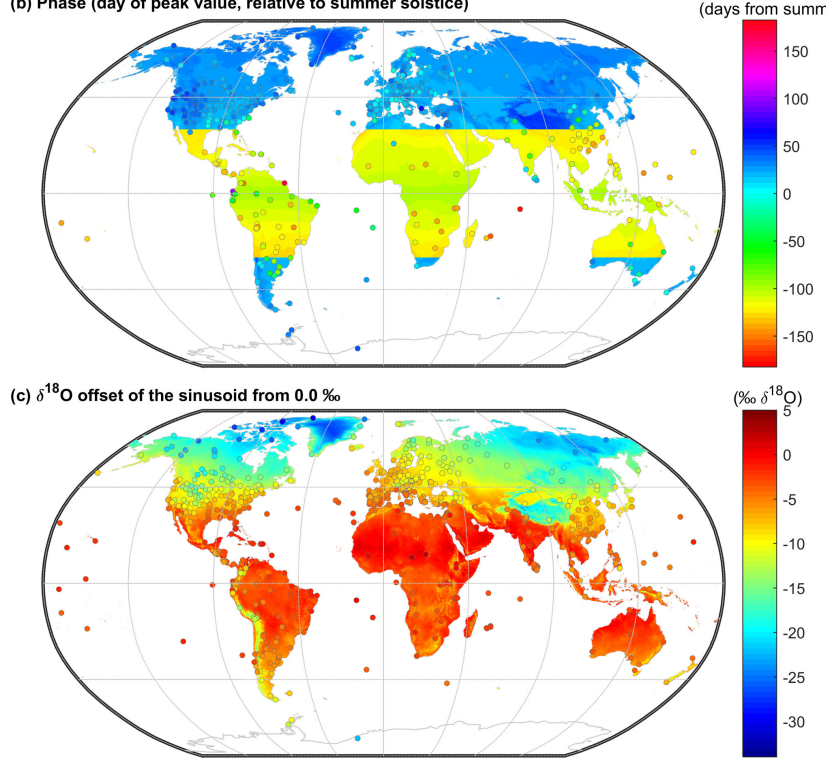

Figure 4. Maps of fitted station values (markers) and regressionbased sine-curve parameters (shaded) that describe the seasonal cycles in precipitation $\delta^{18} \mathrm{O}$ (a) amplitude, (b) phase, and (c) offset. The shading reflects multiple-regression models based on landscape characteristics, described in Table 2; for phase, separate models were used in absolute latitudes $>30^{\circ}$ versus latitudes $<30^{\circ}$ (see methods). Here, residuals were not yet added back into the model.

sented in Table 2 and analogous coefficient tables describing global regression models of $\delta^{2} \mathrm{H}$, amount-weighted $\delta^{18} \mathrm{O}$, and amount-weighted $\delta^{2} \mathrm{H}$ cycles are presented in Table S1 in the Supplement.

Residuals from the interpolated sine parameter layers often show clusters of similar values (Fig. 5), implying that sources of geographic variation are not fully captured by the predictors that we have used. Consequently, regionally calibrated models (calculated over moving $40^{\circ} \times 40^{\circ}$ windows) often yield better fits (Fig. 6). Even in regions where multiple regression models do not effectively explain the variations in precipitation isotope sine parameters (e.g., Central America, south-central Asia), they will necessarily be fitted to the mean regional values, so the regional multiple regression model errors (RMSEs) will usually be smaller than those of the global regression model.
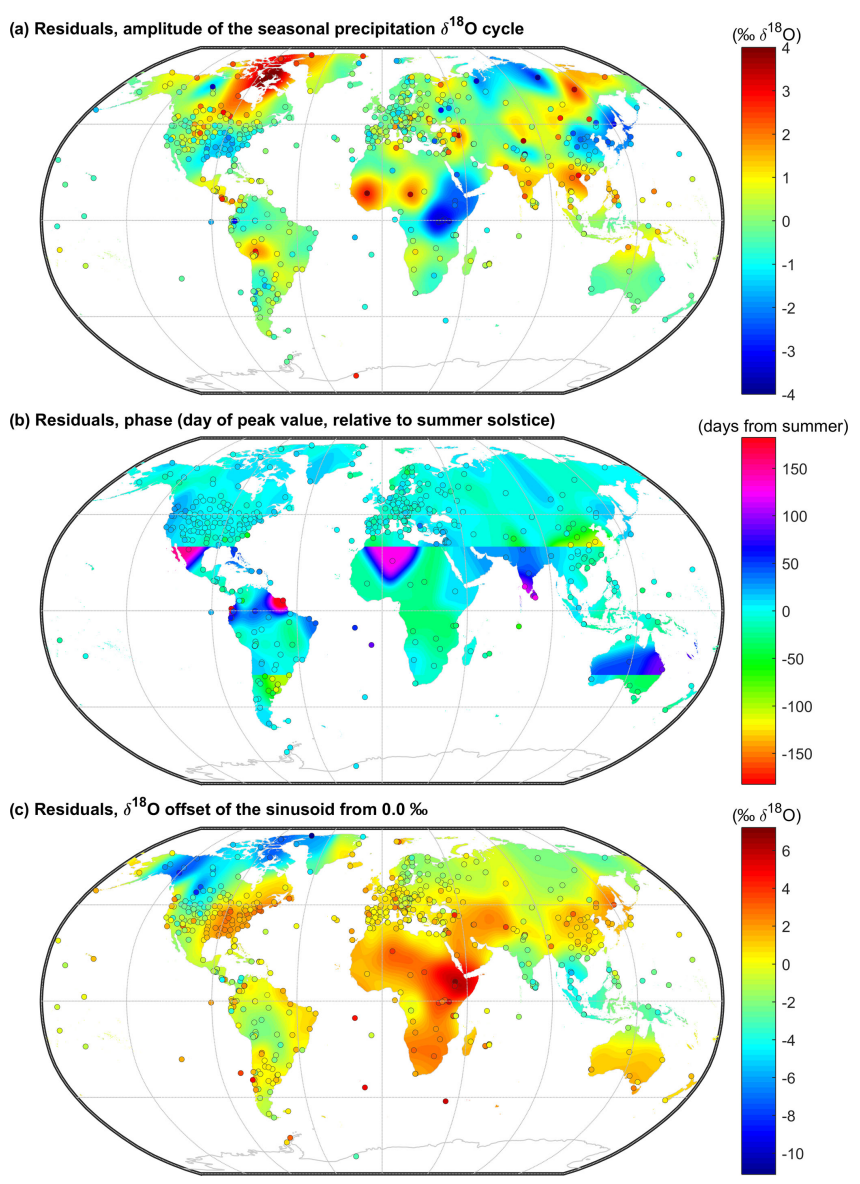

Figure 5. Maps of $\delta^{18} \mathrm{O}$ (a) amplitude, (b) phase, and (c) offset residuals, where the sine parameter values predicted from the multiple regression equations (shown in the interpolated maps in Fig. 4) were subtracted from those of parameter values fitted to measurements at each precipitation isotope monitoring site (also shown in Fig. 4). The shading shows the smoothed residual layers (see Methods).

To produce final predictive maps, we adjusted for the geospatially clustered residuals by adding the smoothed residual maps (Fig. 5) to the regression-based maps (Fig. 4). These predictive sinusoidal maps of $\delta^{18} \mathrm{O}$ seasonality (Fig. 7) and $\delta^{2} \mathrm{H}$ seasonality (Fig. S3) are made available in the Supplement. They capture $88 \%, 97 \%$, and $96 \%$ of the global variations in amplitude, phase, and offset, respectively. To calculate the prediction errors, we ran this routine again but randomly excluded $10 \%$ of the sites from the calibration so that the sine parameters at those sites were predicted independently; the median amplitude and offset errors were $0.49 \% \circ$ and $0.73 \% \circ \delta^{18} \mathrm{O}$ (and $4.0 \%$ and $7.4 \% o \delta^{2} \mathrm{H}$ ), and median phase errors were 8 and $20 \mathrm{~d}$ (for absolute latitudes above and below $30^{\circ}$, respectively). 
(a) Amplitude: regional regression fits

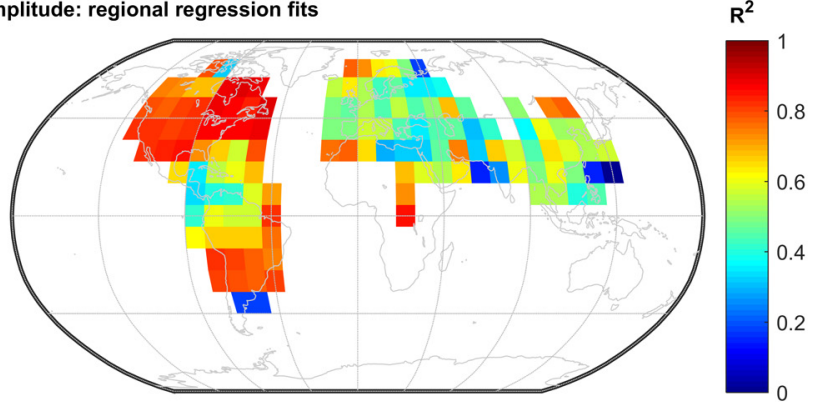

$\mathrm{R}^{2}$

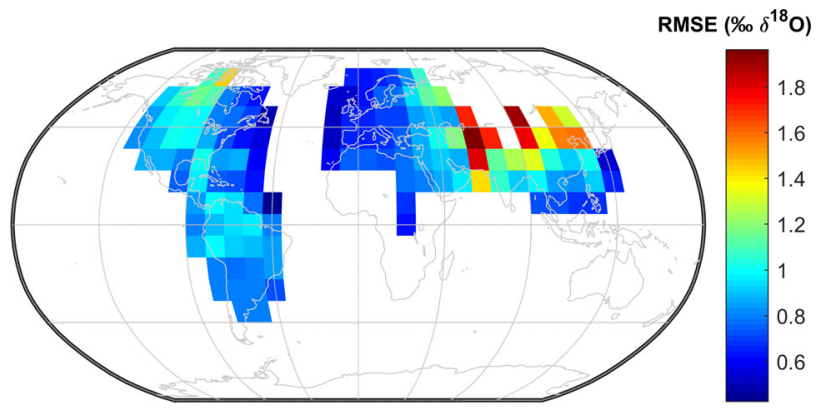

(b) Phase: regional regression fits

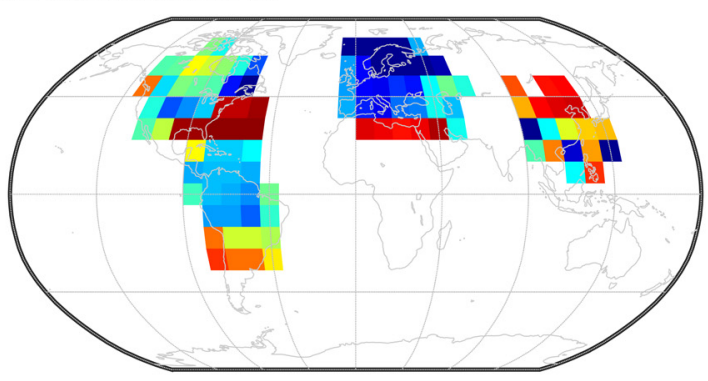

$\mathbf{R}^{2}$

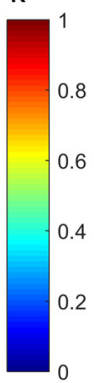

RMSE (d)

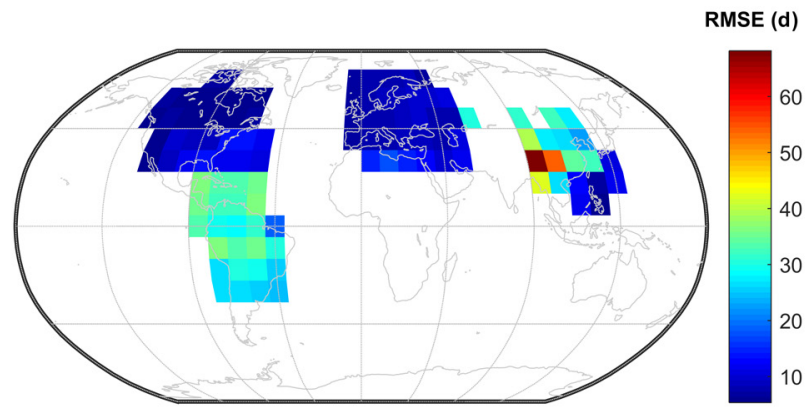

(c) Offset: regional regression fits

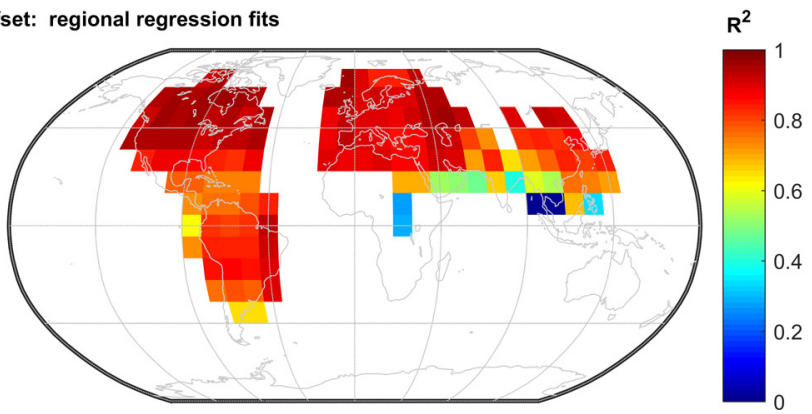

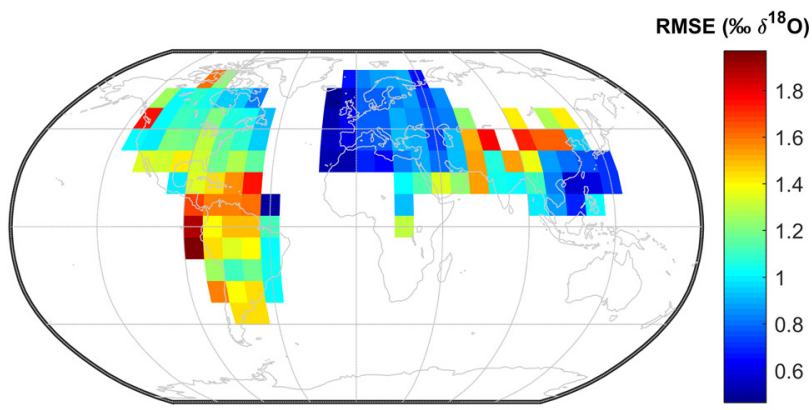

Figure 6. Fit statistics for regionally fitted regressions that explain the spatial variations of the precipitation $\delta^{18} \mathrm{O}$ sine parameters. Regressions of (a) amplitude, (b) phase, and (c) offset versus site characteristics were calculated for $40^{\circ} \times 40^{\circ}$ pixels (centered on vertices at a $10^{\circ}$ grid). Only pixels which contained $>25$ precipitation isotope measurements stations were used; for phase (b), we only used measurement stations that had well-constrained sinusoidal cycles (i.e., the standard error of the phase was less than $15 \mathrm{~d}$ ). These figures show that site characteristics do not consistently explain the patterns of variations, and often the $R^{2}$ values are substantially lower than those of the global regression model (Table 2). However, the errors (RMSEs) are (almost) universally lower than those of the global regression model, implying that regionally calibrated regressions models are better predictors of spatial patterns in precipitation isotope cycles.

\section{Discussion}

The occurrence of seasonal cycles in precipitation isotopes enables the tracking of how precipitation cycles propagate through landscapes and ecosystems. Previous research has found that precipitation isotopes vary seasonally, and that these seasonal patterns vary geographically (Halder et al., 2015; Rozanski et al., 1993). This work quantifies those seasonal patterns and their geographical variation, yielding global maps of sinusoidal precipitation isotope cycles (i.e., global sinusoidal "isoscapes") that can be used to predict sea- sonal precipitation isotope cycles in sites or regions where they have not been measured.

Site characteristics explain most of the global precipitation isotope cyclicity, albeit with uncertainty in the regression model, the sine fits, and the raw data. Amplitude variations are mostly predictable by multiple regression (Table 2), but there were regional clusters of substantive $( \pm 1-$ $2 \% \circ \delta^{18} \mathrm{O}$ ) amplitude residuals. For example, the regression model (Fig. 4) tended to systematically underestimate amplitudes in Canada and the northern United States and systematically overestimate amplitudes in other regions (e.g., southeastern USA, eastern Asia, and eastern Africa). We partially 


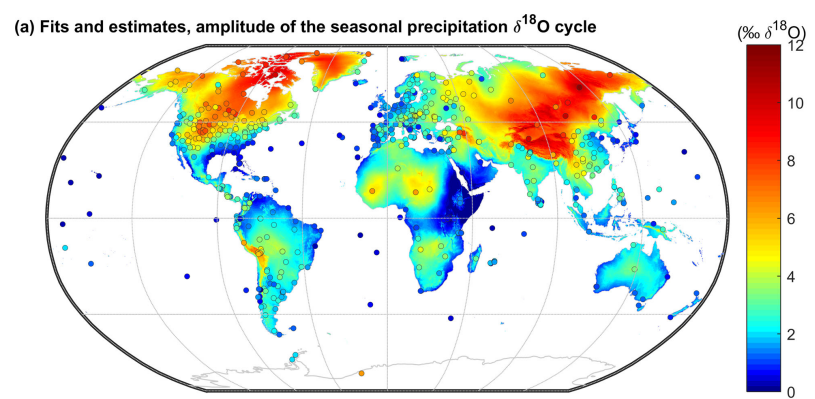

(b) Fits and estimates, phase (day of peak value, relative to summer solstice) (days from summer)
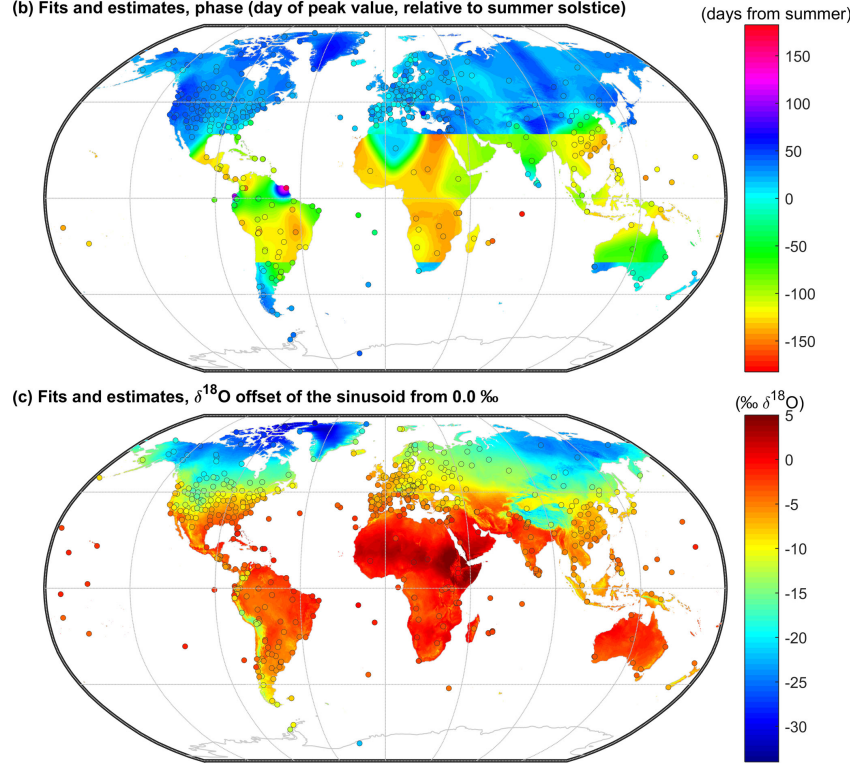

Figure 7. Maps of fitted station values (markers) and the residualadjusted maps of sine-curve parameters (shaded) that describe the seasonal cycles in precipitation $\delta^{18} \mathrm{O}$ : (a) amplitude, (b) phase, and (c) offset. The interpolated surface is the sum of the infilled surfaces in Figs. 3 and 4 (see Methods).

mitigated these discrepancies between model outputs and observations by interpolating and smoothing the residuals, as is commonly done for precipitation isotope maps to improve the fit of the maps to the data (e.g., Terzer et al., 2013). Better fits could have been achievable through using more predictor variables in the regression models; however, we chose to limit the number of variables in the multiple regression models, even prior to the stepwise model selection; while we explored new relationships between precipitation isotope seasonality and (for example) diel temperature range or precipitation amount seasonality (Fig. S1), these offer little explanatory power that is not also captured in simpler metrics. Regardless, some uncertainties are introduced by using gridded climate products to infer site characteristics, because gridcell means are not always representative of individual station locations, as demonstrated by the mismatch between the elevations of monitoring stations and the mean elevations of the pixels they occupy (Fig. S4). Other uncertainties in the regression predictions likely result from errors in the initial sine-curve fitting, as demonstrated by the fact that the regression models improve when only stations with longer records are used. For example, if we exclude all datasets shorter than 3 years (see Fig. 2a), the $R^{2}$ of the $\delta^{18} \mathrm{O}$ amplitude model increases from 0.64 to 0.73 and the $R^{2}$ of the offset model increases from 0.83 to 0.87 . Any uncertainties in the models or the underlying data, however, do not preclude widespread estimation of precipitation stable isotope cycles at the level of confidence indicated (e.g., in Table 2 and Figs. 5 or 2b), which is improved upon through use of the residual-adjusted maps. Predictions can also be improved by using multiple regression models calibrated across individual regions of interest (using the data in Supplement 2).

These maps support predictions of seasonal isotope cycles, but seasonal isotope cycles are only sometimes useful for predicting individual-month isotope values. To predict individual-month isotope values from a sine curve, the sine curve must be predictable (e.g., with well-constrained phase value), but also the sine curve must capture monthly isotope variations (e.g., $R^{2}$ must be high). In only a small subset of the monitoring stations were $R^{2}$ values consistently high (Fig. 2c). For example, at only $6 \%$ of stations was more than $75 \%$ of the variance explained by sine curves. Even fewer stations had long time series that enabled us to determine whether the high $R^{2}$ values also imply that interannual variations are small (e.g., in continental or northern latitude monitoring stations; Fig. 2). Thus, individual month values should be carefully inferred from sine curves (e.g., by assuming errors of magnitudes like those shown in Fig. 2b), even where precipitation isotope seasonality is predictable.

Precipitation isotope cycles are likely to be least predictable in latitudes near $30^{\circ} \mathrm{S}, 0^{\circ}$, or $30^{\circ} \mathrm{N}$, where our models abruptly shift in phase, approximately demarcating global atmospheric circulation patterns. However, the intertropical convergence zone (ITCZ) is not consistently at $0^{\circ}$ and Hadley cell boundaries are not consistently at $30^{\circ} \mathrm{S}$ and $30^{\circ} \mathrm{N}$ (in space or time; Birner et al., 2014; Chen et al., 2014), which may explain why most of the poor phase predictions (Fig. 5b) occur near $30^{\circ} \mathrm{N}$ or $\mathrm{S}$. There are also errors near $0^{\circ}$, where predicted phase values differ by 6 months on either side of the Equator, which does not precisely demarcate the ITCZ and relevant atmospheric circulations. Bowen et al. (2005) recognized this ITCZ effect and instead used the mean ITCZ position, rather than $0^{\circ}$, to account for phase shifts that occur there; although adopting Bowen's approach could mitigate some of the anomalies at 0 and $30^{\circ}$ (Fig. 5), other issues in predicting phase would persist (e.g., the elimination of higher-frequency cycles; Jacobs et al., 2018). Thus, we opt for our simpler approach and accept that our model is sometimes uncertain in zones near 0 and $30^{\circ}$, although those uncertainties are partially mitigated in the residual-adjusted maps.

Shortcomings in regression models may also result from not accounting for storm trajectories or convective effects, both of which influence precipitation isotope ratios (Aggar- 
wal et al., 2016; Hu et al., 2018; Konecky et al., 2019). Models representing those processes can aid in interpreting or predicting stable isotope ratios (Hu et al., 2018; Risi et al., 2010). Furthermore, the variability in tropical precipitation isotope ratios we show here may be the result of different storm sources and cloud types (Bailey et al., 2017; Scholl et al., 2009). Thus, precisely predicting precipitation isotope cycles at low latitudes without calibration data may (especially) require consideration of circulation patterns and their temporal variability (Cai et al., 2018; Martin et al., 2018b); an alternative option would be using regional multiple regression equations, which performed well in those regions (Fig. 6). Regardless, most systematic effects should be compensated for by the residual-smoothing step, as demonstrated by the relatively small prediction errors that we observed.

The 653 isotope monitoring stations used here span much of earth's climatic heterogeneity, but not all regions. The distributions of the site characteristics associated with these 653 monitoring stations are roughly similar to the global distributions of those characteristics (Fig. S5). However, high-latitude, high-elevation monitoring stations are scarce (Fig. S6). More notably, measurements are absent in large regions of Africa, Australia, central Asia, and northern Asia. The most interior regions of continents generally contained the fewest monitoring stations (Fig. 1b), and we suspect that our regression equations may underestimate the true increase in amplitude with distance from oceans (e.g., see amplitude underestimates in continental North America; Fig. 4a). New precipitation isotope monitoring stations would help fill in important gaps.

These maps of seasonal precipitation isotope cycles serve as tools for studying terrestrial processes. In regions where seasonal precipitation isotope dynamics are well described by sine curves, sinusoidal isotope models are useful for predicting isotope values either at explicit points or continuously in time and space. The presence of large seasonal isotope cycles also enables the quantification of mixing, transport, and turnover of water (or its constituent $\mathrm{O}$ and $\mathrm{H}$ ) in landscapes or biota. This is possible because (1) amplitude dampening reflects mixing processes, (2) phase shifts reflect advective travel times, and (3) offset differences reflect proportional contributions of different seasons' precipitation. In hydrology, the proportion of recent precipitation in streams can be estimated as the ratio of precipitation and streamwater isotope amplitudes (i.e., the young water fraction; Kirchner, 2016a). Maps of precipitation isotope cycles can facilitate estimating average precipitation amplitudes across catchments (Dutton et al., 2005; Jasechko et al., 2016). In such cases isotope values should ideally be weighted by precipitation amount, to diminish the influence of low volumes (von Freyberg et al., 2018). Quantifying seasonal precipitation isotope cycles also facilitates identification of the proportion (and over- or underrepresentation) of precipitation from different seasons in samples such as surface waters (Bowen et al., 2019; DeWalle et al., 1997; Halder et al., 2015), groundwa- ter (Jasechko et al., 2014; Kalin and Long, 1994; Lee and Kim, 2007), or plant and soil water (Allen et al., 2019). Similarly, ecological and physiological inferences can be drawn by observing how seasonal variations in water isotope signals are incorporated into (or propagate through) plant and animal tissues (Csank et al., 2016; Gessler et al., 2014; Martin et al., 2018a; Vander Zanden et al., 2015; Yang et al., 2016). Even where phase values are poorly constrained, amplitude and offset values are still useful identifiers of typical mean values and magnitudes of seasonal variation. Thus, we expect that the mapped sine parameters that we have developed, as concise characterizations of seasonal precipitation isotope cycles, will find use in both physical and biological sciences.

These maps also indicate where precipitation isotope seasonality should be considered in interpreting isotopic signals in biological and geological samples. Annual mean precipitation may poorly predict the average isotopic input to any biological or geological process that does not integrate precipitation waters throughout entire years, particularly where precipitation isotopic composition is strongly seasonal (as discussed by, for example, Dutton et al., 2005). Whereas eventto-event variations are likely to be rapidly damped by mixing in soils, lower-frequency variations, such as seasonal cycles, can persist and propagate through the water cycle. Where uptake and incorporation of isotopes into organisms (Balasse et al., 2003; Schubert and Jahren, 2015) or geologic materials (Johnson et al., 2006) also vary seasonally, mean annual precipitation may poorly and inconsistently approximate their average source water. For example, consider a hypothetical case of soil water with an isotopic composition that is consistently equal to that of the current month's mean precipitation. Further assume that a tree growing in this soil takes up that soil water and incorporates its oxygen atoms into cellulose during the 6 months of the warm season (e.g., when high- $\delta{ }^{18} \mathrm{O}$ precipitation falls in high latitudes). For example, if the precipitation $\delta^{18} \mathrm{O}$ has a seasonal amplitude of $4 \%$, the average composition of the water taken up by the tree will be approximately $(2 / \pi) \times 4 \% o \approx 2.5 \%$ o higher than the annual average precipitation. This bias will be larger in locations where the seasonal amplitude of precipitation isotope cycles is larger. Thus, our maps showing precipitation isotope seasonality can be used to identify locations where such biases are potentially significant.

\section{Summary}

The majority of stable isotope time series measured at 653 precipitation isotope monitoring stations show significant sinusoidal seasonal cycles in precipitation isotopes. The fitted parameters that define these seasonal precipitation isotope cycles are estimated through multiple regression models of site characteristics. These spatial models enabled us to develop maps that describe global patterns in precipitation isotope seasonality, although regionally calibrated spatial mod- 
els often better captured regional variations in precipitation isotope seasonality. The global maps and associated fitted isotope data are made available as Supplement.

Data availability. In Supplement 2, we provide all fitted sine curves and site metadata for the 653 precipitation monitoring stations that are presented in this study. In Supplement 3, we provide metadata and a link to a 5 min resolution gridded amplitude, phase, and offset for $\delta^{18} \mathrm{O}$ and $\delta^{2} \mathrm{H}$ of robustly fitted sine curves. All raw data used are synthesized from other studies or publicly available datasets; contact Jeff Welker regarding the USNIP (US Network for Isotopes in Precipitation) dataset at jmwelker@alaska.edu (the website is currently under reconstruction).

Supplement. The supplement related to this article is available online at: https://doi.org/10.5194/hess-23-3423-2019-supplement.

Author contributions. JMW, SJ, and JWK contributed to the collection, compilation, and quality control of the data. STA, SJ, JWK, and GTG conceived the project. STA and SJ executed the analysis, with input from JWK and WRB. STA wrote the paper with contributions from all authors.

Competing interests. The authors declare that they have no conflict of interest.

Acknowledgements. We thank the IAEA for developing and maintaining the Global Network for Isotopes in Precipitation (GNIP) and also thank the many researchers who have contributed data to GNIP. Constructive comments were provided by three reviewers.

Financial support. This project was funded by a grant from the Swiss Federal Office of the Environment to Gregory R. Goldsmith and James W. Kirchner.

Review statement. This paper was edited by Nunzio Romano and reviewed by three anonymous referees.

\section{References}

Aggarwal, P. K., Froehlich, K., and Gonfiantini, R.: Contributions of the International Atomic Energy Agency to the development and practice of isotope hydrology, Hydrogeol J., 19, 5-8, https://doi.org/10.1007/s10040-010-0648-3, 2011.

Aggarwal, P. K., Romatschke, U., Araguas-Araguas, L., Belachew, D., Longstaffe, F. J., Berg, P., Schumacher, C., and Funk, A.: Proportions of convective and stratiform precipitation revealed in water isotope ratios, Nat. Geosci., 9, 624-629, https://doi.org/10.1038/ngeo2739, 2016.
Allen, S. T., Kirchner, J. W. and Goldsmith, G. R.: Predicting spatial patterns in precipitation isotope $(\delta 2 \mathrm{H}$ and $\delta 18 \mathrm{O})$ seasonality using sinusoidal isoscapes, Geophys. Res. Lett., 4859-4868, https://doi.org/10.1029/2018GL077458, 2018.

Allen, S. T., Kirchner, J. W., Braun, S., Siegwolf, R. T. W., and Goldsmith, G. R.: Seasonal origins of soil water used by trees, Hydrol. Earth Syst. Sci., 23, 1199-1210, https://doi.org/10.5194/hess-23-1199-2019, 2019.

Bailey, A., Blossey, P. N., Noone, D., Nusbaumer, J., and Wood, R.: Detecting shifts in tropical moisture imbalances with satellitederived isotope ratios in water vapor, J. Geophys. Res.-Atmos., 122, 5763-5779, https://doi.org/10.1002/2016JD026222, 2017.

Balasse, M., Smith, A. B., Ambrose, S. H., and Leigh, S. R.: Determining Sheep Birth Seasonality by Analysis of Tooth Enamel Oxygen Isotope Ratios: The Late Stone Age Site of Kasteelberg (South Africa), J. Archaeol. Sci., 30, 205-215, https://doi.org/10.1006/jasc.2002.0833, 2003.

Berghuijs, W. R. and Woods, R. A.: A simple framework to quantitatively describe monthly precipitation and temperature climatology, Int. J. Climatol., 36, 3161-3174, https://doi.org/10.1002/joc.4544, 2016.

Birks, S. J. and Edwards, T. W. D.: Atmospheric circulation controls on precipitation isotope-climate relations in western Canada, Tellus B, 61, 566-576, https://doi.org/10.1111/j.16000889.2009.00423.x, 2009.

Birks, S. J. and Gibson, J. J.: Isotope Hydrology Research in Canada, 2003-2007, Can. Water Resour. J., 34, 163-176, https://doi.org/10.4296/cwrj3402163, 2013.

Birner, T., Davis, S. M., and Seidel, D. J.: The changing width of Earth's tropical belt, Phys. Today, 67, 38, https://doi.org/10.1063/PT.3.2620, 2014.

Bowen, G. J.: Spatial analysis of the intra-annual variation of precipitation isotope ratios and its climatological corollaries, J. Geophys. Res., 113, D05113, https://doi.org/10.1029/2007JD009295, 2008.

Bowen, G. J. and Revenaugh, J.: Interpolating the isotopic composition of modern meteoric precipitation, Water Resour. Res., 39, 1299, https://doi.org/10.1029/2003WR002086, 2003.

Bowen, G. J. and Wilkinson, B.: Spatial distribution of $\delta^{18} \mathrm{O}$ in meteoric precipitation, Geology, 30, 315-318, https://doi.org/10.1130/00917613(2002)030<0315:SDOOIM>2.0.CO;2, 2002.

Bowen, G. J., Wassenaar, L. I., and Hobson, K. A.: Global application of stable hydrogen and oxygen isotopes to wildlife forensics, Oecologia, 143, 337-348, https://doi.org/10.1007/s00442004-1813-y, 2005.

Bowen, G. J., Liu, Z., Vander Zanden, H. B., Zhao, L., and Takahashi, G.: Geographic assignment with stable isotopes in IsoMAP, Methods Ecol. Evol., 5, 201-206, https://doi.org/10.1111/2041-210X.12147, 2014.

Bowen, G. J., Cai, Z., Fiorella, R. P., and Putman, A. L.: Isotopes in the Water Cycle: Regional- to Global-Scale Patterns and Applications, Annu. Rev. Earth Pl. Sc., 47, 453-479, https://doi.org/10.1146/annurev-earth-053018-060220, 2019.

Cai, Z., Tian, L., and Bowen, G. J.: Spatial-seasonal patterns reveal large-scale atmospheric controls on Asian Monsoon precipitation water isotope ratios, Earth Planet. Sc. Lett., 503, 158-169, https://doi.org/10.1016/j.epsl.2018.09.028, 2018. 
Chen, S., Wei, K., Chen, W., and Song, L.: Regional changes in the annual mean Hadley circulation in recent decades, J. Geophys. Res.-Atmos., 119, 7815-7832, https://doi.org/10.1002/2014JD021540, 2014.

Clow, D. W., Mast, M. A., and Sickman, J. O.: Linking transit times to catchment sensitivity to atmospheric deposition of acidity and nitrogen in mountains of the western United States, Hydrol. Proc., 32, 2456-2470, https://doi.org/10.1002/hyp.13183, 2018.

Csank, A. Z., Miller, A. E., Sherriff, R. L., Berg, E. E., and Welker, J. M.: Tree-ring isotopes reveal drought sensitivity in trees killed by spruce beetle outbreaks in south-central Alaska, Ecol. Appl., 26, 2001-2020, https://doi.org/10.1002/eap.1365, 2016.

Dansgaard, W.: Stable isotopes in precipitation, Tellus, 16, 436468, https://doi.org/10.1111/j.2153-3490.1964.tb00181.x, 1964.

Delavau, C., Chun, K. P., Stadnyk, T., Birks, S. J., and Welker, J. M.: North American precipitation isotope $(\delta 18 \mathrm{O})$ zones revealed in time series modeling across Canada and northern United States, Water Resour. Res., 51, 1284-1299, https://doi.org/10.1002/2014WR015687, 2015.

DeWalle, D. R., Edwards, P. J., Swistock, B. R., Aravena, R., and Drimmie, R. J.: Seasonal isotope hydrology of three Appalachian forest catchments, Hydrol. Proc., 11, 1895-1906, 1997.

Dutton, A., Wilkinson, B. H., Welker, J. M., Bowen, G. J., and Lohmann, K. C.: Spatial distribution and seasonal variation in ${ }^{18} \mathrm{O} /{ }^{16} \mathrm{O}$ of modern precipitation and river water across the conterminous USA, Hydrol. Process., 19, 4121-4146, https://doi.org/10.1002/hyp.5876, 2005.

Feng, X., Faiia, A. M., and Posmentier, E. S.: Seasonality of isotopes in precipitation: A global perspective, J. Geophys. Res.Atmos., 114, D08116, https://doi.org/10.1029/2008JD011279, 2009.

Fick, S. E. and Hijmans, R. J.: WorldClim 2: new 1-km spatial resolution climate surfaces for global land areas, Int. J. Climatol., 37, 4302-4315, https://doi.org/10.1002/joc.5086, 2017.

Gessler, A., Ferrio, J. P., Hommel, R., Treydte, K., Werner, R. A., and Monson, R. K.: Stable isotopes in tree rings: towards a mechanistic understanding of isotope fractionation and mixing processes from the leaves to the wood, Tree Physiol., 34, 796-818, https://doi.org/10.1093/treephys/tpu040, 2014.

Halder, J., Terzer, S., Wassenaar, L. I., Araguás-Araguás, L. J., and Aggarwal, P. K.: The Global Network of Isotopes in Rivers (GNIR): integration of water isotopes in watershed observation and riverine research, Hydrol. Earth Syst. Sci., 19, 3419-3431, https://doi.org/10.5194/hess-19-3419-2015, 2015.

$\mathrm{Hu}$, J., Emile-Geay, J., Nusbaumer, J. and Noone, D.: Impact of Convective Activity on Precipitation $\delta^{18} \mathrm{O}$ in Isotope-Enabled General Circulation Models, J. Geophys. Res.-Atmos., 123, 13595-13610, https://doi.org/10.1029/2018JD029187, 2018.

Jacobs, S. R., Timbe, E., Weeser, B., Rufino, M. C., ButterbachBahl, K., and Breuer, L.: Assessment of hydrological pathways in East African montane catchments under different land use, Hydrol. Earth Syst. Sci., 22, 4981-5000, https://doi.org/10.5194/hess-22-4981-2018, 2018.

Jasechko, S., Birks, S. J., Gleeson, T., Wada, Y., Fawcett, P. J., Sharp, Z. D., McDonnell, J. J., and Welker, J. M.: The pronounced seasonality of global groundwater recharge, Water Resour. Res., 50, 8845-8867, https://doi.org/10.1002/2014WR015809, 2014.
Jasechko, S., Kirchner, J. W., Welker, J. M., and McDonnell, J. J.: Substantial proportion of global streamflow less than three months old, Nat. Geosci., 9, 126-129, https://doi.org/10.1038/ngeo2636, 2016.

Jasechko, S., Wassenaar, L. I., and Mayer, B.: Isotopic evidence for widespread cold-season-biased groundwater recharge and young streamflow across central Canada, Hydrol. Proc., 31, 2196-2209, https://doi.org/10.1002/hyp.11175, 2017.

Johnson, K. R., Hu, C., Belshaw, N. S., and Henderson, G. M.: Seasonal trace-element and stable-isotope variations in a Chinese speleothem: The potential for high-resolution paleomonsoon reconstruction, Earth Pl. Sci. Lett., 244, 394-407, https://doi.org/10.1016/j.epsl.2006.01.064, 2006.

Kalin, R. M. and Long, A.: Application of hydrogeochemical modelling for validation of hydrologic flow modelling in the Tucson basin aquifer, Arizona, United States of America, International Atomic Energy Agency, Proceedings of a final research co-ordination meeting held in Vienna, 1-4 June 1993, 1994.

Kirchner, J. W.: Aggregation in environmental systems - Part 1: Seasonal tracer cycles quantify young water fractions, but not mean transit times, in spatially heterogeneous catchments, Hydrol. Earth Syst. Sci., 20, 279-297, https://doi.org/10.5194/hess20-279-2016, 2016a.

Kirchner, J. W.: Aggregation in environmental systems - Part 2: Catchment mean transit times and young water fractions under hydrologic nonstationarity, Hydrol. Earth Syst. Sci., 20, 299 328, https://doi.org/10.5194/hess-20-299-2016, 2016 b.

Konecky, B. L., Noone, D. C., and Cobb, K. M.: The Influence of Competing Hydroclimate Processes on Stable Isotope Ratios in Tropical Rainfall, Geophys. Res. Lett., 46, 1622-1633, https://doi.org/10.1029/2018GL080188, 2019.

Landwehr, J. M. and Coplen, T. B.: Line-conditioned excess: A new method for characterizing stable hydrogen and oxygen isotope ratios in hydrologic systems, 132-135, 2006.

Lee, K.-S. and Kim, Y.: Determining the seasonality of groundwater recharge using water isotopes: a case study from the upper North Han River basin, Korea, Environ. Geol., 52, 853-859, https://doi.org/10.1007/s00254-006-0527-3, 2007.

Lutz, S. R., Krieg, R., Müller, C., Zink, M., Knöller, K., Samaniego, L., and Merz, R.: Spatial Patterns of Water Age: Using Young Water Fractions to Improve the Characterization of Transit Times in Contrasting Catchments, Water Resour. Res., 54, 4767-4784, https://doi.org/10.1029/2017WR022216, 2018.

Marquaridt, D. W.: Generalized Inverses, Ridge Regression, Biased Linear Estimation, and Nonlinear Estimation, Technometrics, 12, 591-612, https://doi.org/10.1080/00401706.1970.10488699, 1970.

Martin, J., Looker, N., Hoylman, Z., Jencso, K., and Hu, J.: Differential use of winter precipitation by upper and lower elevation Douglas fir in the Northern Rockies, Global Change Biol., 24, 5607-5621, https://doi.org/10.1111/gcb.14435, 2018a.

Martin, N. J., Conroy, J. L., Noone, D., Cobb, K. M., Konecky, B. L., and Rea, S.: Seasonal and ENSO Influences on the Stable Isotopic Composition of Galápagos Precipitation, J. Geophys. Res.Atmos., 123, 261-275, https://doi.org/10.1002/2017JD027380, 2018 b.

Pfahl, S. and Sodemann, H.: What controls deuterium excess in global precipitation?, Clim. Past, 10, 771-781, https://doi.org/10.5194/cp-10-771-2014, 2014. 
Price, R. M., Swart, P. K., and Willoughby, H. E.: Seasonal and spatial variation in the stable isotopic composition $\left(\delta^{18} \mathrm{O}\right.$ and $\delta$ D) of precipitation in south Florida, J. Hydrol., 358, 193-205, https://doi.org/10.1016/j.jhydrol.2008.06.003, 2008.

Risi, C., Bony, S., Vimeux, F., and Jouzel, J.: Water-stable isotopes in the LMDZ4 general circulation model: Model evaluation for present-day and past climates and applications to climatic interpretations of tropical isotopic records, J. Geophys. Res.-Atmos., 115, D12118, https://doi.org/10.1029/2009JD013255, 2010.

Rozanski, K., Araguás-Araguás, L., and Gonfiantini, R.: Isotopic Patterns in Modern Global Precipitation, in: Climate Change in Continental Isotopic Records, edited by: P. K. Swart, K. C. Lohmann, J. Mckenzie, and Savin, S., American Geophysical Union, 1-36, 1993.

Scholl, M. A., Shanley, J. B., Zegarra, J. P., and Coplen, T. B.: The stable isotope amount effect: New insights from NEXRAD echo tops, Luquillo Mountains, Puerto Rico, Water Resour. Res., 45, W12407, https://doi.org/10.1029/2008WR007515, 2009.

Schubert, B. A. and Jahren, A. H.: Seasonal temperature and precipitation recorded in the intra-annual oxygen isotope pattern of meteoric water and tree-ring cellulose, Quaternary Sci. Rev., 125, 1-14, https://doi.org/10.1016/j.quascirev.2015.07.024, 2015.

Song, C., Wang, G., Liu, G., Mao, T., Sun, X., and Chen, X.: Stable isotope variations of precipitation and streamflow reveal the young water fraction of a permafrost watershed, Hydrol. Proc., 31, 935-947, https://doi.org/10.1002/hyp.11077, 2017.

Terzer, S., Wassenaar, L. I., Araguás-Araguás, L. J., and Aggarwal, P. K.: Global isoscapes for $\delta^{18} \mathrm{O}$ and $\delta^{2} \mathrm{H}$ in precipitation: improved prediction using regionalized climatic regression models, Hydrol. Earth Syst. Sci., 17, 4713-4728, https://doi.org/10.5194/hess-17-4713-2013, 2013.

US Geological Survey: Global 30 Arc-Second Elevation (GTOPO30), US Geological Survey, Center for Earth Resources Observation and Science (EROS), https://doi.org/10.5066/F7DF6PQS, 1996.

Vachon, R. W., White, J. W. C., Gutmann, E. and Welker, J. M.: Amount-weighted annual isotopic $\left(\delta^{18} \mathrm{O}\right)$ values are affected by the seasonality of precipitation: A sensitivity study, Geophys. Res. Lett., 34, L21707, https://doi.org/10.1029/2007GL030547, 2007.
Vander Zanden, H. B., Wunder, M. B., Hobson, K. A., Van Wilgenburg, S. L., Wassenaar, L. I., Welker, J. M., and Bowen, G. J.: Space-time tradeoffs in the development of precipitation-based isoscape models for determining migratory origin, J. Avian. Biol., 46, 658-667, https://doi.org/10.1111/jav.00656, 2015.

von Freyberg, J., Allen, S. T., Seeger, S., Weiler, M., and Kirchner, J. W.: Sensitivity of young water fractions to hydro-climatic forcing and landscape properties across 22 Swiss catchments, Hydrol. Earth Syst. Sci., 22, 3841-3861, https://doi.org/10.5194/hess-223841-2018, 2018.

Welker, J. M.: Isotopic $\left(\delta^{18} \mathrm{O}\right)$ characteristics of weekly precipitation collected across the USA: an initial analysis with application to water source studies, Hydrol. Proc., 14, 1449-1464, https://doi.org/10.1002/1099-1085(20000615)14:8<1449::AIDHYP993>3.0.CO;2-7, 2000.

Welker, J. M.: ENSO effects on $\delta^{18} \mathrm{O}, \delta^{2} \mathrm{H}$ and d-excess values in precipitation across the U.S. using a high-density, longterm network (USNIP), Rapid Comm. Mass Sp., 26, 1893-1898, https://doi.org/10.1002/rcm.6298, 2012.

Wessel, P. and Smith, W. H. F.: A global, self-consistent, hierarchical, high-resolution shoreline database, J. Geophys. Res.-Sol Ea., 101, 8741-8743, https://doi.org/10.1029/96JB00104, 1996.

West, J. B., Bowen, G. J., Dawson, T. E., and Tu, K. P. (Eds.): Isoscapes: Understanding movement, pattern, and process on Earth through isotope mapping, Springer Netherlands, available at: https://www.springer.com/gp/book/9789048133536 (last access: 8 October 2018), 2010.

Wilkinson, B. H. and Ivany, L. C.: Paleoclimatic inference from stable isotope profiles of accretionary biogenic hardparts - a quantitative approach to the evaluation of incomplete data, Palaeogeogr. Palaeocl., 185, 95-114, https://doi.org/10.1016/S00310182(02)00279-1, 2002.

Yang, L. H., Ostrovsky, D., Rogers, M. C., and Welker, J. M.: Intrapopulation variation in the natal origins and wing morphology of overwintering western monarch butterflies Danaus plexippus, Ecography, 39, 998-1007, https://doi.org/10.1111/ecog.01994, 2016. 